\title{
Quality-of-Life Outcomes, Effectiveness and Tolerability of Apremilast in Patients with Plaque Psoriasis and Routine German Dermatology Care: Results from LAPIS-PSO
}

\author{
Kristian Reich · Bernhard Korge · Nina Magnolo • Maria Manasterski • \\ Uwe Schwichtenberg • Petra Staubach-Renz · Stephan Kaiser • \\ Josefine Roemmler-Zehrer · Natalie Núnez Gómez • Katrin Lorenz-Baath
}

Received: June 11, 2021 / Accepted: November 27, 2021 / Published online: December 15, 2021

(C) The Author(s) 2021

\section{ABSTRACT}

Introduction: Psoriasis is a systemic inflammatory disease characterised by pruritic skin lesions that impair quality of life (QOL). LongTerm Documentation of the Utilization of Apremilast in Patients with Plaque Psoriasis under Routine Conditions (LAPIS-PSO; ClinicalTrials.gov: NCT02626793) was a 52-week, prospective, multicentre, observational cohort study conducted in real-world dermatology clinical settings in Germany. We evaluated physician- and patient-reported outcomes for

Supplementary Information The online version contains supplementary material available at https:// doi.org/10.1007/s13555-021-00658-x.

\section{K. Reich (两)}

Translational Research in Inflammatory Skin Diseases, Institute for Health Services Research in Dermatology and Nursing, University Medical Center Hamburg-Eppendorf, Martinistraße 52, Building West 38/Room 514, 20246 Hamburg, Germany

e-mail: k.reich@uke.de

\section{B. Korge}

Hautarztpraxis Priv. Doz. Dr. med. Bernhard Korge, Düren, Germany

N. Magnolo

Department of Dermatology, University Hospital Muenster, Münster, Germany
QOL, effectiveness and tolerability in patients with moderate to severe psoriasis vulgaris in LAPIS-PSO.

Methods: The primary endpoint was the percentage of patients achieving Dermatology Life Quality Index (DLQI) score $\leq 5$ or $\geq 5$-point improvement from baseline in DLQI score at visit 2 ( 4 months after baseline). Secondary endpoints included assessments of symptoms and disease severity. Tolerability was evaluated based on adverse events (AEs). A pre-defined subgroup analysis based on baseline Physician's Global Assessment (PGA) score ( 2 or 3 versus 4 ) was performed. Data were examined descriptively through visit 5 ( $\sim 13$ months) using the lastobservation-carried-forward (LOCF) approach and data as observed.

\author{
M. Manasterski \\ Hautarztpraxis Manasterski und Dues, Berlin, \\ Germany \\ U. Schwichtenberg \\ Derma Nord Hautarztpraxen Dr. med. \\ Schwichtenberg, Bremen, Germany \\ P. Staubach-Renz \\ Department of Dermatology, University Medical \\ Center, Mainz, Germany \\ S. Kaiser · J. Roemmler-Zehrer · K. Lorenz-Baath \\ Amgen GmbH, München, Germany \\ N. N. Gómez \\ Bristol Myers Squibb, Summit, NJ, USA
}


Results: In total, 257 patients were included for efficacy assessment. On LOCF analysis, most patients achieved the primary endpoint at visit 2 (66.5\%); DLQI response was maintained at visit $5(72.4 \%)$. Earlier treatment response was observed in patients with a PGA score of 2 or 3 versus 4 (visit 1 PASI $\leq 3: 20.5 \%$ versus $10.8 \%$ ). Adverse events were consistent with the known safety profile of apremilast.

Conclusions: In routine clinical care in Germany, patients with moderate to severe plaque psoriasis benefited from apremilast treatment up to $\sim 13$ months, consistent with findings from clinical trials, with a good safety profile.

Keywords: Apremilast; Psoriasis; Real-world; Observational; Quality of life; Patient-reported outcome measures; Effectiveness; Pruritus

\section{Key Summary Points}

\section{Why carry out this study?}

The burden of psoriasis, which often affects visible and sensitive special areas (e.g., scalp, palmoplantar areas, nails), may not be fully captured by traditional measures of disease severity, and many patients with moderate disease are undertreated

Apremilast is an oral phosphodiesterase 4 inhibitor that has demonstrated efficacy and tolerability in patients with moderate to severe plaque psoriasis in clinical trials, including improvements in quality of life and efficacy for psoriasis in special areas; however, less is known about effectiveness and quality-of-life outcomes with apremilast in clinical practice

\section{What did the study ask?}

The Long-Term Documentation of the Utilization of Apremilast in Patients with Plaque Psoriasis under Routine Conditions (LAPIS-PSO; NCT02626793), conducted in dermatology clinical settings in Germany, evaluated the real-world effectiveness and tolerability of apremilast treatment, including assessments of patient-reported outcomes

\section{What was learned from the study?}

In LAPIS-PSO, apremilast treatment was well tolerated and demonstrated sustained improvements in quality of life, psoriasis in special areas, symptoms (itch and pain) and overall disease severity up to $\sim 13$ months of treatment, including in patients with less severe and more severe psoriasis

These findings from clinical practice were consistent with results from apremilast clinical trials and confirm that apremilast can benefit patients who have high disease burden due to psoriasis involvement in special areas and bothersome symptoms such as itch and skin pain

\section{INTRODUCTION}

Psoriasis is a chronic, systemic, inflammatory disease characterised by pruritic and painful skin lesions [1-3] that often occur in highly sensitive or visible special areas, such as the scalp, palmoplantar areas or nails [4], and can result in physical disability and quality-of-life (QOL) impairments [5-7]. Disease burden may not be fully captured by traditional measures of disease severity such as psoriasis-involved body surface area (BSA) or Psoriasis Area and Severity Index (PASI) $[4,5]$, resulting in undertreatment among patients with moderate skin involvement [8]. Consensus guidelines suggest complementing physician-rated assessments with patient-reported outcomes when evaluating treatment effectiveness [5]. 
Long-term management of moderate to severe psoriasis may involve conventional systemic treatment, biologic therapy or a targeted oral systemic agent such as apremilast [9, 10]. Apremilast is an oral phosphodiesterase 4 inhibitor that regulates the inflammatory response in psoriasis by targeting cytokines implicated in psoriasis pathogenesis [11]. Apremilast was approved in Europe in January 2015 for treatment of moderate to severe chronic plaque psoriasis in adults who failed to respond to, have a contraindication to, or are intolerant to other systemic therapy, including cyclosporine, methotrexate or phototherapy [12]. In placebocontrolled trials, apremilast showed efficacy and tolerability in patients with moderate to severe plaque psoriasis, including improvements in QOL and efficacy for psoriasis in special areas [13-17]. Less is known about the effectiveness of apremilast in real-world settings. Patients treated in real-world settings are generally different from those who meet stringent eligibility criteria for phase 3 clinical trials [18]. Studies that evaluate the use of apremilast in routine clinical practice can help inform treatment decisions. A recent European real-world study suggests that, despite its second-line indication, apremilast is often used in patients with more moderate disease than patients included in the pivotal clinical trials [12-14, 19]. The Long-Term Documentation of the Utilization of Apremilast in Patients with Plaque Psoriasis under Routine Conditions (LAPIS-PSO; NCT02626793) characterised patients who receive apremilast in realworld dermatology clinical settings in Germany, including assessment of patient-reported outcomes. We report findings of this 52-week, prospective, multicentre, observational cohort study that evaluated effectiveness and safety outcomes in patients with moderate to severe plaque psoriasis who received apremilast according to the Summary of Product Characteristics (SmPC).

\section{METHODS}

\section{Patient Population}

Eligibility was based on the apremilast SmPC; the decision to treat was made by the treating physician prior to and independently of inclusion in the study. Adult patients ( $\geq 18$ years) diagnosed with moderate to severe psoriasis vulgaris were eligible for enrolment. Eligible patients had inadequate response to or intolerance to $\geq 1$ prior systemic therapy or contraindication of systemic therapies. Patients previously treated with biologics were excluded.

\section{Study Design}

LAPIS-PSO was a prospective, multicentre, observational cohort study conducted in realworld dermatology clinical settings across Germany; physicians with real-world study experience who represented a balanced regional distribution were included. Data collection occurred between August 3, 2015 and June 14, 2018. Study visits were timed according to physicians' clinical practice, with no strict study visit schedule. To facilitate systematic data analysis, the following time windows for study visits were suggested: optional visit 1,1 month; visit 2, 4 months; visit 3, 7 months; visit 4, 10 months; visit 5 (end of observation), 13 months (Supplementary Fig. 1).

An independent ethics committee (FEKI; Freiburger Ethikkommission International, reference 015/1385) approved the study protocol, and all patients provided written, informed consent before participating. Local ethics committees approved the protocol for participating study sites (UK RUB Ruhruniversität Bochum, reference 52/2015; Sächsische Landesärztkammer, reference RN EK-BR-74/15-1; Medizinische Fakultät Mannheim, reference 2015-905W-MA; Ethikkommission der Technischen Universität Dresden, reference EK472112015; Medizinische Fakultät der Universität Duisburg-Essen, reference 16-6844-BO). The study was conducted in accordance with the ethical principles outlined in the Declaration of Helsinki and its amendments. 


\section{Endpoints}

The primary endpoint was achievement of Dermatology Life Quality Index (DLQI) response (score $\leq 5$ or improvement from baseline in DLQI score $\geq 5$ points) at visit 2 . DLQI response was evaluated at all study visits. Achievement of DLQI score categories [0-1 (no impairment), 2-5 (minimal impairment), 6-10 (moderate impairment), 11-20 (high impairment), 21-30 (highest impairment)] and mean changes from baseline in DLQI score and BSA were also assessed. Other response endpoints [i.e., achievement of 0 (clear) or 1 (almost clear) using a 5-point scale up to 4 (severe)] were: scalp PGA (ScPGA; baseline ScPGA > 0); palmoplantar PGA (PPPGA; baseline PPPGA > 0); and Nail Psoriasis Severity Index (NAPSI) score in the target (worst) fingernail (tNAPSI; baseline NAPSI $>0$ ). Percentage changes from baseline in pruritus and skin pain visual analogue scale (VAS) scores $(0-100 \mathrm{~mm} ; 0=$ no pain/itching, $100=$ worst pain/itching imaginable) were evaluated at all study visits. Patient satisfaction was assessed at visit 2 using the Patient Therapy Preference Questionnaire (PPQ). Safety was assessed throughout the study on the basis of adverse events (AEs). Physicians recorded all AEs orally mentioned by the patient or noticed by study personnel, starting with the first apremilast dose until $\geq 28$ days after the last dose; AEs were recorded within $24 \mathrm{~h}$ of the physician becoming aware of the event.

\section{Statistical Analyses}

Safety analyses were summarised descriptively in the safety analysis population, which included all patients who received one or more doses of apremilast. Effectiveness and QOL were examined descriptively in the full analysis population, defined as all patients in the safety analysis population with DLQI score $>5$ at baseline who had DLQI data available at visit 2. A sample of $\sim 500$ patients was planned for assessment of the primary endpoint with an accuracy within \pm 6 percentage points based on a two-sided 95\% confidence interval (CI), assuming 58\% of patients having data to analyse for the primary endpoint (i.e. 290 patients) and $60 \%$ of patients achieving the primary endpoint. Data were analysed using the last-observation-carried-forward (LOCF) approach to impute missing values and as observed without imputation. To calculate DLQI response rates, missing values were imputed using LOCF for patients who did not attend any study visits but did not drop out early and for patients who dropped out early due to clinical improvement; for patients who dropped out early for another reason, missing values were classified as non-responders.

In the pre-specified subgroup analysis by baseline Physician's Global Assessment (PGA) category $(\mathrm{PGA}=2$ or 3 versus $\mathrm{PGA}=4)$, achievement of DLQI response and mean BSA and PASI were assessed at all study visits. Achievement of PASI $\leq 3$ by baseline PGA category was assessed at all study visits.

\section{RESULTS}

\section{Patients}

A total of 391 patients at 75 sites were enrolled; 364 patients met inclusion criteria for the safety population, and 257 patients were evaluated for efficacy in the full analysis population (Supplementary Fig. 2). Among 179 patients in the safety analysis population who discontinued early, common reasons for discontinuation were lack of efficacy $[n / N=97 / 391(24.8 \%)]$ and AEs $[n / N=41 / 391 \quad(10.5 \%)]$ (Supplementary Fig. 2). The majority of patients who discontinued treatment $[81.2 \%(95 / 117)]$ started a new psoriasis therapy, and $18.8 \%(22 / 117)$ terminated their therapy fully.

Patient demographics and characteristics at baseline were generally similar in the full analysis and safety populations (Table 1, Supplementary Table 1). In the full analysis population, $68.9 \%(177 / 257)$ of patients had a PGA score of 2 or 3 (moderate) and 28.8\% (74/ 257 ) of patients had a PGA score of 4 (severe); $98.4 \%(249 / 253)$ of patients reported itch as a symptom, scalp psoriasis was present in $80.3 \%$ (204/254) of patients, $51.2 \%$ of patients had nail involvement (131/256) and $26.5 \%(66 / 249)$ of patients had palmoplantar psoriasis (Table 1). 
Table 1 Baseline demographics and patient characteristics in the full analysis population

\begin{tabular}{|c|c|c|c|}
\hline Characteristic & $\begin{array}{l}\text { Full analysis population } \\
N=257\end{array}$ & $\begin{array}{l}\text { Baseline } \\
\text { PGA }=2 \text { or } 3 \\
N=177\end{array}$ & $\begin{array}{l}\text { Baseline } \\
\text { PGA =4 } \\
N=74\end{array}$ \\
\hline Female, \% & 46.7 & 48.0 & 40.5 \\
\hline Age at inclusion, mean (SD), year & $51.1(13.2)$ & $50.8(13.5)$ & $51.4(13.0)$ \\
\hline Duration of psoriasis, mean (SD), year & $21.0(15.8)$ & $21.2(16.0)$ & $20.7(15.6)$ \\
\hline BMI, mean (SD), $\mathrm{kg} / \mathrm{m}^{2}$ & $28.6(6.0)$ & $28.1(5.8)$ & $30.1(6.4)$ \\
\hline Erythrodermic psoriasis, $n / N(\%)$ & $5 / 232(2.2)$ & $1 / 156(0.6)$ & $4 / 70(5.7)$ \\
\hline Guttate psoriasis, $n / N(\%)$ & $27 / 243(11.1)$ & $23 / 167(13.8)$ & $3 / 70(4.3)$ \\
\hline Inverse psoriasis, $n / N(\%)$ & $40 / 240(16.7)$ & $28 / 164(17.1)$ & $12 / 70(17.1)$ \\
\hline Scalp involvement, $n / N(\%)$ & $204 / 254(80.3)$ & $139 / 174(79.9)$ & $60 / 74(81.1)$ \\
\hline Nail involvement ${ }^{\mathrm{a}}, n / N(\%)$ & $131 / 256(51.2)$ & $88 / 176(50.0)$ & $41 / 74(55.4)$ \\
\hline Palmoplantar involvement, $n / N(\%)$ & $66 / 249(26.5)$ & $33 / 170(19.4)$ & $30 / 73(41.1)$ \\
\hline Pruritus, $n / N(\%)$ & $249 / 253(98.4)$ & $173 / 175(98.9)$ & $71 / 73(97.3)$ \\
\hline \multicolumn{4}{|l|}{ Comorbidities (> 5\%), $n / N(\%)$} \\
\hline Cardiovascular disorders & $98 / 257(38.1)$ & $65 / 177(36.7)$ & $30 / 74(40.5)$ \\
\hline Hypertension & $87 / 257(33.9)$ & $60 / 177(33.9)$ & $25 / 74(33.8)$ \\
\hline Coronary heart disease & $21 / 257(8.2)$ & $13 / 177(7.3)$ & $8 / 74(10.8)$ \\
\hline Other & $10 / 257(3.9)$ & $7 / 177(4.0)$ & $2 / 74(2.7)$ \\
\hline Peripheral artery disease & $4 / 257(1.6)$ & $2 / 177(1.1)$ & $2 / 74(2.7)$ \\
\hline Dyslipidaemia & $36 / 257(14.0)$ & $21 / 177(11.9)$ & $14 / 74(18.9)$ \\
\hline Diabetes mellitus & $23 / 257(8.9)$ & $11 / 177(6.2)$ & $11 / 74(14.9)$ \\
\hline Confirmed depression & $21 / 257(8.2)$ & $11 / 177(6.2)$ & $10 / 74(13.5)$ \\
\hline Hepatic disorder & $16 / 257(6.2)$ & $8 / 177(4.5)$ & $7 / 74(9.5)$ \\
\hline Other & $80 / 257(31.1)$ & $51 / 177(28.8)$ & $26 / 74(35.1)$ \\
\hline \multicolumn{4}{|l|}{ Previous psoriasis therapy, $n / N(\%)$} \\
\hline \multicolumn{4}{|l|}{ Topical therapies } \\
\hline Glucocorticosteroids & $195 / 257(75.9)$ & $131 / 177(74.0)$ & $61 / 74(82.4)$ \\
\hline Vitamin D analogues & $163 / 257(63.4)$ & $106 / 177(59.9)$ & $55 / 74(74.3)$ \\
\hline Salicylic acid & $105 / 257(40.9)$ & $67 / 177(37.9)$ & $36 / 74(48.6)$ \\
\hline Urea & $76 / 257(29.6)$ & $47 / 177(26.6)$ & $27 / 74(36.5)$ \\
\hline Dithranol & $48 / 257(18.7)$ & $29 / 177(16.4)$ & $19 / 74(25.7)$ \\
\hline Other & $11 / 257(4.3)$ & $7 / 177(4.0)$ & $4 / 74(5.4)$ \\
\hline Vitamin A analogues & $6 / 257(2.3)$ & $4 / 177(2.3)$ & $2 / 74(2.7)$ \\
\hline
\end{tabular}


Table 1 continued

\begin{tabular}{llll}
\hline Characteristic & $\begin{array}{l}\text { Full analysis population } \\
\boldsymbol{N}=\mathbf{2 5 7}\end{array}$ & $\begin{array}{l}\text { Baseline } \\
\text { PGA } \mathbf{2} \text { or } \mathbf{3} \\
\boldsymbol{N = \mathbf { 1 7 7 }}\end{array}$ & $\begin{array}{l}\text { Baseline } \\
\text { PGA }=\mathbf{4} \\
\boldsymbol{N}=\mathbf{7 4}\end{array}$ \\
\hline $\begin{array}{l}\text { Systemic therapies and phototherapy, } n / N(\%) \\
\text { Fumaric acid ester }\end{array}$ & $127 / 177(71.8)$ & $46 / 74(62.2)$ \\
Methotrexate & $175 / 257(68.1)$ & $91 / 177(51.4)$ & $37 / 74(50.0)$ \\
UVA/UVB & $130 / 257(50.6)$ & $82 / 177(46.3)$ & $43 / 74(58.1)$ \\
Psoralen + UVA (PUVA) & $126 / 257(49.0)$ & $47 / 177(26.6)$ & $18 / 74(24.3)$ \\
Cyclosporine & $66 / 257(25.7)$ & $29 / 177(16.4)$ & $14 / 74(18.9)$ \\
Glucocorticosteroids & $44 / 257(17.1)$ & $12 / 177(6.8)$ & $10 / 74(13.5)$ \\
Retinoids & $22 / 257(8.6)$ & $5 / 177(2.8)$ & $4 / 74(5.4)$ \\
Leflunomide & $9 / 257(3.5)$ & $2 / 177(1.1)$ & $1 / 74(1.4)$ \\
Other & $3 / 257(1.2)$ & $9 / 177(5.1)$ & $1 / 74(1.4)$ \\
\hline
\end{tabular}

$N$ represents the total sample; number of patients with data available may vary. Percentages represent data for patients with baseline values

$B M I$ body mass index, $P G A$ Physician's Global Assessment, SD standard deviation

${ }^{a}$ Physician-documented nail involvement at baseline

Most patients had prior treatment with topical or systemic therapies. Almost 90\% of patients had baseline PGA or Patient's Global Assessment (PaGA) scores $\geq 3$, and many had baseline ScPGA or PPPGA scores $\geq 3$ [61.6\% $(125 / 203)$ and $41.8 \%$ (28/67), respectively; Table 2]. At baseline and all study visits, the median apremilast dose was $30 \mathrm{mg}$ twice daily, in accordance with the label.

Demographics were generally similar between the PGA severity subgroups and the full analysis population (Table 1). The proportions of patients with psoriasis involvement in the scalp or nails were similar between patients with PGA of 2 or 3 and those with PGA of 4 (scalp: $79.9 \%$ and $81.1 \%$; nail: $50.0 \%$ and 55.4\%); palmoplantar involvement was less prevalent in patients with PGA of 2 or 3 (19.4\%) versus PGA of 4 (41.1\%) (Table 1). Despite higher PASI among patients with a PGA score of 4, baseline mean DLQI and pruritus VAS scores were generally similar in the two groups (Table 2).

\section{Effects of Apremilast on QOL}

In the full analysis population, $66.5 \%(171 / 257)$ of patients achieved the primary endpoint of DLQI response with apremilast treatment (Fig. 1a). More than $50 \%$ of patients achieved DLQI response as early as visit 1, and results were generally similar at subsequent study visits (Fig. 1a). The proportions of patients with DLQI improvement of $\geq 5$ points increased over time, from $48.2 \%(124 / 257)$ at visit 1 to $66.9 \%$ (172/ 257 ) at visit 5 (LOCF). Improvements in mean DLQI scores increased with each subsequent study visit (Supplementary Table 2). In the full analysis population, improvements in mean BSA were observed over time with continued apremilast treatment (Supplementary Table 2). Achievement of DLQI scores corresponding to no or minimal QOL impairment (DLQI $\leq 5$ ) increased over time and was reached by $54.5 \%$ $(140 / 257)$ of patients at visit 5 (LOCF) (Supplementary Fig. 3). 
Table 2 Baseline disease characteristics in the full analysis population

\begin{tabular}{|c|c|c|c|}
\hline Characteristic & $\begin{array}{l}\text { Full analysis population } \\
N=257\end{array}$ & $\begin{array}{l}\text { Baseline } \\
\text { PGA }=2 \text { or } 3 \\
N=177\end{array}$ & $\begin{array}{l}\text { Baseline } \\
\text { PGA =4 } \\
N=74\end{array}$ \\
\hline DLQI score, mean (SD) & $14.1(5.9)$ & $13.3(5.5)$ & $16.1(6.5)$ \\
\hline PASI, mean $(S D)$ & $15.1(10.2)$ & $11.7(6.3)$ & $24.0(12.2)$ \\
\hline BSA, mean (SD), \% & $21.8(18.5)$ & $16.7(13.3)$ & $35.6(22.3)$ \\
\hline PGA score, mean (SD) & $3.1(0.7)$ & $2.9(0.4)$ & $4.0(0.0)$ \\
\hline $\mathrm{PGA}=3^{\mathrm{a}}, n / N(\%)$ & $225 / 256(87.9)$ & $151 / 177(85.3)$ & $0 / 74$ \\
\hline PaGA score, mean $(\mathrm{SD})$ & $3.3(0.8)$ & $3.2(0.8)$ & $3.6(0.5)$ \\
\hline $\mathrm{PaGA} \geq 3, n / N(\%)$ & $228 / 256(89.1)$ & $154 / 176(87.5)$ & $73 / 74(98.6)$ \\
\hline ScPGA score, mean (SD) & $2.7(0.9)$ & $2.6(0.8)$ & $2.9(1.0)$ \\
\hline $\mathrm{ScPGA} \geq 3, n / N(\%)$ & $125 / 203(61.6)$ & $82 / 141(58.2)$ & $42 / 59(71.2)$ \\
\hline PPPGA score, mean (SD) & $2.3(1.1)$ & $2.1(1.0)$ & $2.5(1.1)$ \\
\hline PPPGA score $\geq 3, n / N(\%)$ & $28 / 67(41.8)$ & $12 / 34(35.3)$ & $15 / 32(46.9)$ \\
\hline Target $\mathrm{NAPSI}^{\mathrm{b}}$, mean $(\mathrm{SD})$ & $4.1(2.3)$ & $3.9(2.1)$ & $4.6(2.5)$ \\
\hline Pruritus VAS score, mean (SD), mm & $56.6(26.1)$ & $55.0(25.4)$ & $60.6(27.5)$ \\
\hline Skin pain VAS score, mean (SD), mm & $36.6(26.6)$ & $34.4(25.8)$ & $41.8(27.7)$ \\
\hline
\end{tabular}

$N$ represents the total sample; number of patients with data available may vary. Percentages represent data for patients with baseline values

$B S A$ psoriasis-involved body surface area, DLQI Dermatology Life Quality Index, NAPSI Nail Psoriasis Severity Index, PaGA Patient's Global Assessment, PASI Psoriasis Area and Severity Index, PGA Physician's Global Assessment, PPPGA Palmoplantar Psoriasis Physician's Global Assessment, ScPGA Scalp Physician's Global Assessment, $S D$ standard deviation, $V A S$ visual analogue scale

${ }^{a} \mathrm{PGA} \geq 3$ in the full analysis population; PGA $=3$ in the PGA subgroup analysis

${ }^{\mathrm{b}}$ Of the most involved nail

\section{Effects of Apremilast on Disease Severity Assessments}

In the full analysis population, mean (SD) PASI scores were $7.8(8.1)$ at visit 2 and 4.3 (5.2) at visit 5. The proportion of patients achieving PASI responses increased over time. The PASI-50 response rate was $53.9 \%(96 / 178)$ at visit 2 and increased to $80.0 \%(84 / 105)$ at visit 5 . The PASI75 response rate was $27.5 \%(49 / 178)$ at visit 2 and increased to $50.5 \%(53 / 105)$ at visit 5 . The PASI90 response rate was $12.4 \%(22 / 178)$ at visit 2 and increased to $30.5 \%(32 / 105)$ at visit 5 .

The proportion of patients with PGA score of 0 was $1.2 \%(3 / 256)$ at baseline and increased to
$4.9 \%(11 / 226)$ at visit 2 and $10.0 \%(13 / 130)$ at visit 5 .

\section{Subgroup Analysis by Baseline PGA Severity}

According to baseline PGA categorisation, DLQI response (LOCF) was achieved by $52.5 \%(93 /$ 177) of patients with a score of 2 or 3 and $59.5 \%$ $(44 / 74)$ of patients with a score of 4 at visit 1 . DLQI response rates were similar over time for patients in both PGA severity subgroups, and DLQI improvement was mostly maintained up to visit 5 (Fig. 1b). Continuous improvements in 
a

DLQI Response
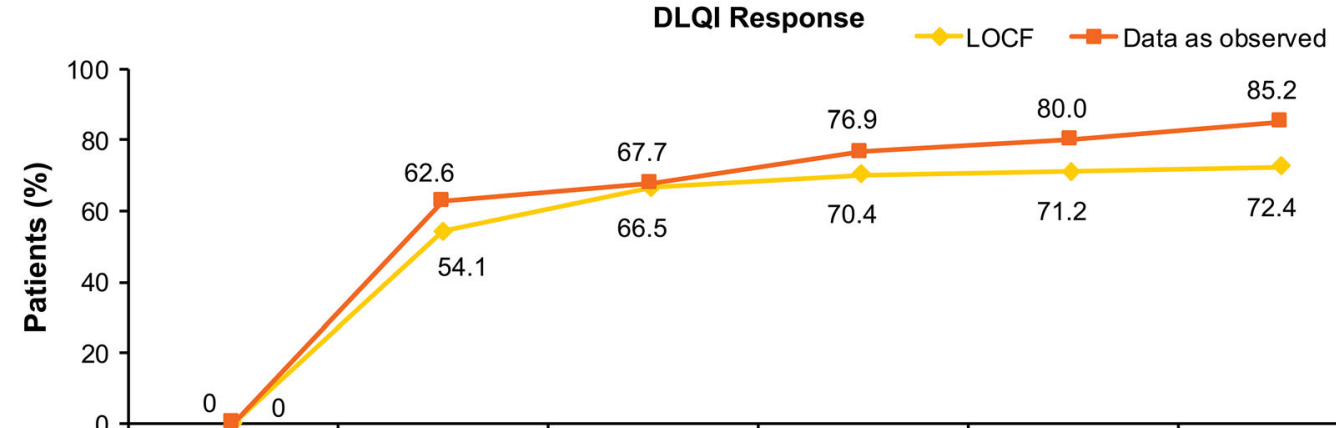

54.1

\begin{tabular}{|c|c|c|c|c|c|c|}
\hline & Baseline & $\begin{array}{c}\text { Visit 1 } \\
\text { ( 1 Month } \\
\text { After BL) }\end{array}$ & $\begin{array}{c}\text { Visit } 2 \\
\text { ( 4 Months } \\
\text { After BL) }\end{array}$ & $\begin{array}{c}\text { Visit } 3 \\
(\sim 7 \text { Months } \\
\text { After BL) }\end{array}$ & $\begin{array}{c}\text { Visit } 4 \\
\text { ( } \sim 10 \text { Months } \\
\text { After } B L)\end{array}$ & $\begin{array}{c}\text { Visit } 5 \\
\text { ( } 13 \text { Months } \\
\text { After BL) }\end{array}$ \\
\hline $\mathrm{n} / \mathrm{N}$ for LOCF & $0 / 257$ & $139 / 257$ & $171 / 257$ & $181 / 257$ & $183 / 257$ & $186 / 257$ \\
\hline $\begin{array}{c}\mathrm{n} / \mathrm{N} \text { for data as } \\
\text { observed }\end{array}$ & $0 / 257$ & $139 / 222$ & $149 / 220$ & $130 / 169$ & $108 / 135$ & $109 / 128$ \\
\hline
\end{tabular}

\begin{tabular}{|c|c|c|c|c|c|c|}
\hline & Baseline & Visit 1 & Visit 2 & Visit 3 & Visit 4 & Visit 5 \\
\hline LOCF, mean (SD) & $14.1(5.9)$ & $9.0(6.4)$ & $7.1(5.8)$ & $6.5(5.9)$ & $6.6(6.0)$ & $6.6(6.0)$ \\
\hline $\begin{array}{l}\text { Data as observed, } \\
\text { mean (SD) }\end{array}$ & $14.1(5.9)$ & $8.2(6.0)$ & $6.7(5.5)$ & $5.2(5.0)$ & $4.9(4.7)$ & $4.7(4.8)$ \\
\hline
\end{tabular}

b

DLQI Response, LOCF $\quad \checkmark-$ Baseline PGA $=2$ or 3

\begin{tabular}{|c|c|c|c|c|c|c|}
\hline 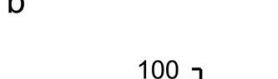 & & & DLQI Respons & se, LOCF & $\begin{array}{l}- \text {-Baseline } \\
- \text {-Baseline }\end{array}$ & $\begin{array}{l}\mathrm{GA}=2 \text { or } 3 \\
\mathrm{GA}=4\end{array}$ \\
\hline 80 & & & 70.3 & 71.6 & 74.3 & 75.7 \\
\hline & & & $\Rightarrow$ & 701 & & $\Rightarrow$ \\
\hline & Baseline & $\begin{array}{l}\text { Visit } 1 \\
\text { ( 1 Month } \\
\text { After BL) }\end{array}$ & $\begin{array}{c}\text { Visit } 2 \\
\text { ( 4 Months } \\
\text { After BL) }\end{array}$ & $\begin{array}{c}\text { Visit } 3 \\
\text { ( 7 Months } \\
\text { After BL) }\end{array}$ & $\begin{array}{c}\text { Visit } 4 \\
\text { ( 10 Months } \\
\text { After BL) }\end{array}$ & $\begin{array}{c}\text { Visit } 5 \\
\text { ( 13 Months } \\
\text { After BL) }\end{array}$ \\
\hline $\begin{array}{l}\mathrm{n} / \mathrm{N} \text { for baseline } \\
\mathrm{PGA}=2 \text { or } 3\end{array}$ & $0 / 177$ & $93 / 177$ & $116 / 177$ & $124 / 177$ & $124 / 177$ & $126 / 177$ \\
\hline $\begin{array}{l}\mathrm{n} / \mathrm{N} \text { for baseline } \\
\mathrm{PGA}=4\end{array}$ & $0 / 74$ & $44 / 74$ & $52 / 74$ & $53 / 74$ & $55 / 74$ & $56 / 74$ \\
\hline & & DLQI Res & ponse, Data as ob & served & & \\
\hline & Baseline & Visit 1 & Visit 2 & Visit 3 & Visit 4 & Visit 5 \\
\hline $\begin{array}{l}\text { Baseline } P G A=2 \text { or } 3 \\
n / N(\%)\end{array}$ & $0 / 177(0.0)$ & $93 / 148(62.8)$ & $101 / 150(67.3)$ & $90 / 117(76.9)$ & $72 / 94(76.6)$ & $73 / 88(83.0)$ \\
\hline $\begin{array}{l}\text { Baseline PGA=4, } \\
\mathrm{n} / \mathrm{N}(\%)\end{array}$ & $0 / 74(0.0)$ & $44 / 70(62.9)$ & $45 / 64(70.3)$ & $37 / 48(77.1)$ & 33/37 (89.2) & $34 / 37(91.9)$ \\
\hline & & & lean DLQI Score & & & \\
\hline & Baseline & Visit 1 & Visit 2 & Visit 3 & Visit 4 & Visit 5 \\
\hline LOCF & & & & & & \\
\hline $\begin{array}{l}\text { Baseline PGA=2 or } 3 \text {, } \\
\text { mean (SD) }\end{array}$ & $13.3(5.5)$ & $8.5(5.8)$ & $6.6(5.5)$ & $6.0(5.3)$ & $6.2(5.3)$ & $6.2(5.5)$ \\
\hline $\begin{array}{l}\text { Baseline PGA=4, } \\
\text { mean (SD) }\end{array}$ & $16.1(6.5)$ & $10.1(7.6)$ & $8.0(6.6)$ & $7.3(6.8)$ & $7.5(6.9)$ & $7.4(6.7)$ \\
\hline Data as observed & & & & & & \\
\hline $\begin{array}{l}\text { Baseline PGA=2 or } 3 \text {, } \\
\text { mean (SD) }\end{array}$ & $13.3(5.5)$ & $7.6(5.4)$ & $6.4(5.3)$ & $4.8(4.5)$ & $5.2(4.6)$ & $4.9(5.1)$ \\
\hline $\begin{array}{l}\text { Baseline PGA=4, } \\
\text { mean (SD) }\end{array}$ & $16.1(6.5)$ & $9.4(7.1)$ & $7.4(5.9)$ & $5.6(5.6)$ & $4.3(5.0)$ & $4.2(4.2)$ \\
\hline
\end{tabular}


4Fig. 1 Percentage of patients achieving the primary endpoint of DLQI response (DLQI $\leq 5$ or DLQI improvement $\geq 5$ ) in a the full analysis population and b by PGA severity subgroup $(N=257)$. a Data are from the full analysis population. For the as-observed analysis, $n /$ $N=$ number of patients who achieved response/number of patients with available data. b For the as-observed analysis, $n / N=$ number of patients who achieved response/number of patients with available data. $B L$ baseline, DLQI Dermatology Life Quality Index, $L O C F$ last observation carried forward, $P G A$ Physician's Global Assessment, $S D$ standard deviation

mean BSA and PASI were observed from visit 1 to visit 5 in the full population and in both PGA severity subgroups (Supplementary Fig. 4). Earlier treatment response was observed in patients with a PGA score of 2 or 3, with a greater percentage achieving PASI $\leq 3$ as early as visit 1 and at each study visit thereafter compared with patients with severe psoriasis (Fig. 2). Rates of treatment discontinuation were similar in both groups [PGA score of 2 or 3: 48.8\% (131/268); PGA score of $4: 50.6 \%(42 / 83)]$.

\section{Effects of Apremilast on Special Areas and Symptoms of Psoriasis}

Patients with scalp, palmoplantar and nail psoriasis at baseline demonstrated continuous improvements in clinical assessments at each study visit up to visit 4, which were mostly maintained at visit 5 (Fig. 3). In patients with scalp and palmoplantar involvement at baseline, respectively, the majority of patients achieved ScPGA [54.7\% (111/203)] or PPPGA [71.6\% (48/67)] score of 0 or 1 at visit 5 (LOCF; Fig. 3a, b). Approximately one-third of patients [35.6\% (42/118)] with nail involvement at baseline had tNAPSI score of 0 at visit 5 (LOCF; Fig. 3c).

Improvements in pruritus VAS scores exceeding the minimal clinically important

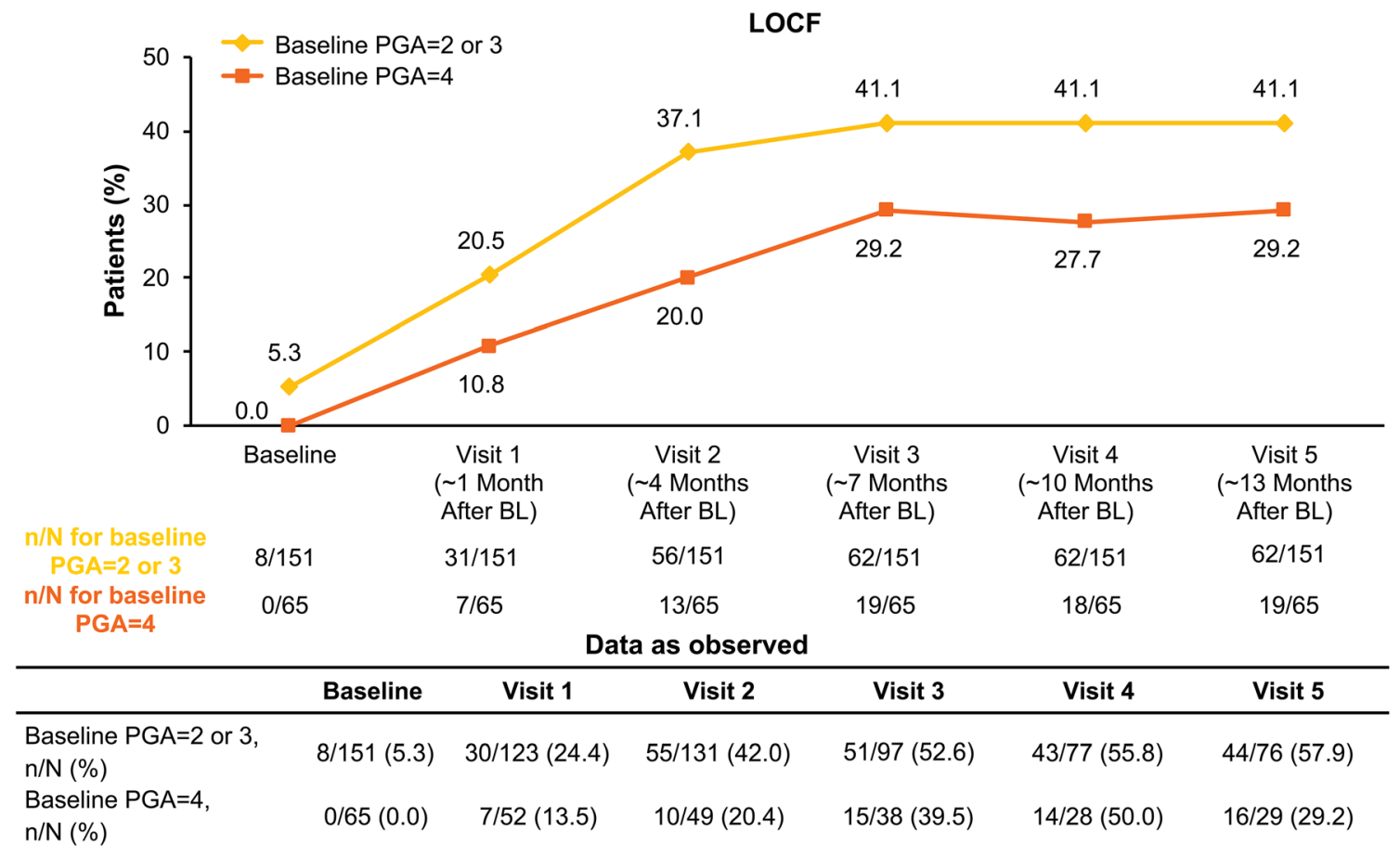

Fig. 2 Percentage of patients achieving PASI $\leq 3$ by PGA severity subgroup. Data are from the full analysis population $(N=257)$. For as-observed analysis, $n / N=$ number of patients who achieved response/number of patients with available data. $B L$ baseline, PASI Psoriasis Area and Severity Index, $P G A$ Physician's Global Assessment 
a

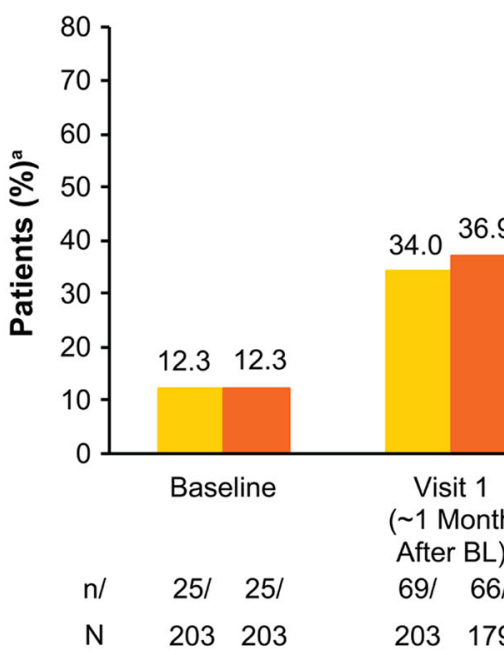

ScPGA 0 or 1

LOCF Data as observed

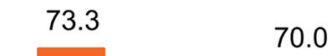


4 Fig. 3 Percentage of patients achieving a ScPGA score of 0 or $1, \mathbf{b}$ PPPGA score of 0 or 1 , or $\mathbf{c}$ tNAPSI score of 0 in the full analysis population. ${ }^{a}$ Patients achieving ScPGA or PPPGA score of 0 (clear) or 1 (almost clear) or tNAPSI score of 0. Data are from the full analysis population $(N=257) . n / N=$ number of patients who achieved response/number of patients with available data. $B L$ baseline, PPPGA Palmoplantar Psoriasis Physician's Global Assessment, ScPGA Scalp Physician's Global Assessment, NAPSI Nail Psoriasis Severity Index, tNAPSI NAPSI in the target nail

difference of $>20 \%$ improvement [20] were observed as early as visit 1 and continued over time (Fig. 4a). Similarly, early and sustained improvements in skin pain VAS were observed (Fig. 4b). At visit 5, large improvements were noted in both pruritus and skin pain VAS scores with apremilast treatment (Fig. 4).

At visit 2, many patients strongly agreed that they preferred apremilast [64.3\% (133/207)] and considered it to be better tolerated than their prior systemic treatment [59.1\% (123/208), data as observed], as evaluated using the PPQ (Supplementary Fig. 5).

\section{Safety and Tolerability}

Median apremilast exposure during the study ( $n=364$ ) was 0.9 years (329 days), corresponding to 294 patient-years. AEs were reported in $39.8 \%(145 / 364)$ of patients in the safety analysis population; $28.0 \%(102 / 364)$ reported AEs considered to be related to apremilast treatment (Table 3). The majority of treatment-related AEs were mild in severity, and there were few reports of serious treatment-related AEs (Table 3). Less than 9\% of patients experienced AEs leading to treatment discontinuation (Table 3).

Four patients reported treatment-related serious AEs, including one serious AE leading to death (completed suicide); the other treatmentrelated serious AEs were seizure $(n=1)$, bronchitis $(n=1)$ and weight loss $(n=1)$ (Table 3$)$. Relevant medical history and outcomes for patients who had treatment-related serious AEs are provided in Table 3 .
One death was reported in a patient who had been diagnosed with acute myeloid leukaemia (AML) before starting apremilast. The cause of death reported by the investigator was deterioration/progression of AML. This AE was not considered to be related to apremilast treatment.

In all, 32 patients discontinued treatment due to AEs; AEs occurring in $>1 \%$ of patients who discontinued were diarrhoea $[1.9 \%$ (7/ $364)]$ and headache $[1.6 \%(6 / 364)]$. The incidence of treatment-emergent AEs in the LAPISPSO study for AEs commonly reported in clinical trials of apremilast (i.e. diarrhoea, nausea, headache and upper respiratory tract infection) are presented in Table 3. For treatment-emergent AEs commonly reported in clinical trials, incidence rates per 100 patient-years were low in LAPIS-PSO, and the median time to first occurrence of these AEs was within the first 2 weeks of treatment (Table 3).

Overall, the incidence rate for depression related to apremilast treatment was 1.7 per 100 patient-years. There were 5/364 patients $(1.4 \%)$ who reported treatment-related AEs of depression that were moderate in severity. Three patients had a diagnosis of depression at baseline; of these, two patients required treatment for depression. A total of three patients with AEs of depression discontinued apremilast treatment (two of these patients had a prior history of depression), and their depression improved to the level reported at baseline after discontinuing apremilast treatment.

\section{DISCUSSION}

In patients with moderate to severe plaque psoriasis receiving routine clinical care in Germany in LAPIS-PSO, apremilast treatment was well tolerated and had a positive impact on clinical assessments and patient-reported outcomes. Patients achieved early improvement in DLQI and pruritus VAS scores at $\sim 1$ month, and improvements were maintained with continued apremilast treatment. Sustained improvements on global assessments of disease severity were observed through $\sim 13$ months of continuous treatment. A high proportion of 


\section{a Pruritus VAS}

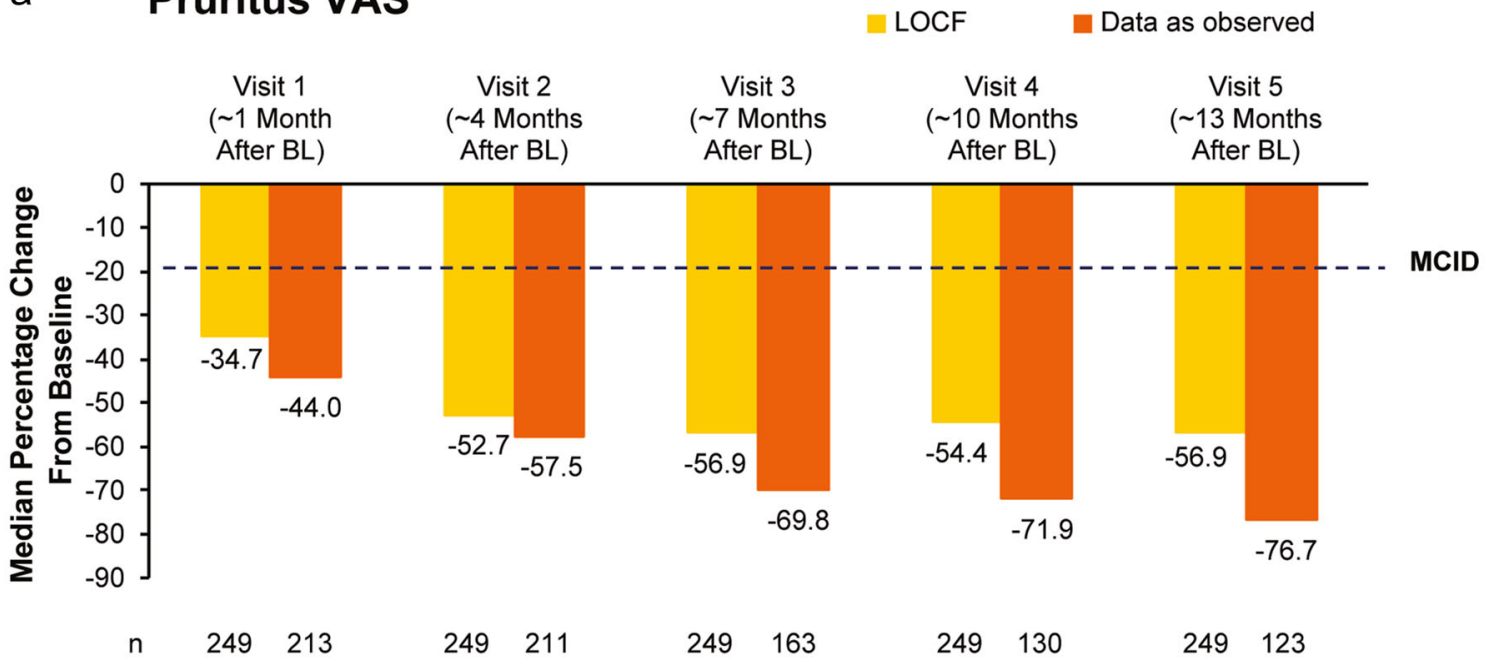

b Skin Pain VAS

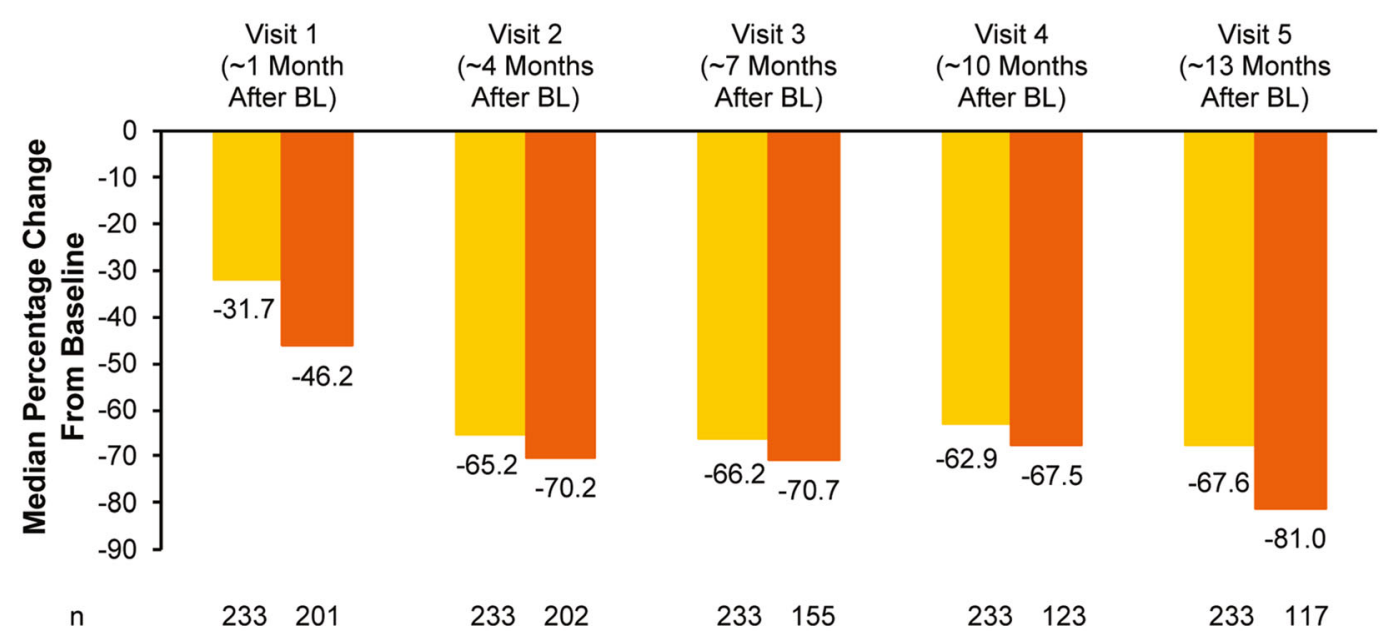

Fig. 4 Change from baseline in a pruritus VAS and $\mathbf{b}$ skin pain VAS scores in the full analysis population. Data are from the full analysis population $(N=257)$. $N$ number of patients with available data, $B L$ baseline, $V A S$ visual analogue scale

patients with scalp or palmoplantar psoriasis achieved total or almost complete clearance in these special areas. These real-world findings confirm the effectiveness of apremilast demonstrated in clinical trials [13-16] and other realworld apremilast studies in moderate to severe plaque psoriasis [21-23].

In LAPIS-PSO, the patient population had somewhat lower disease severity at baseline based on mean BSA (21.8\%) and PASI (15.1) than patients in the pooled ESTEEM 1 and 2 $(24.8 \%, 18.8 \%)$ phase 3 studies of apremilast in moderate to severe plaque psoriasis. Mean pruritus and pain VAS scores were lower at baseline in the current study $(56.6 \mathrm{~mm}, 36.6 \mathrm{~mm}) \mathrm{com}$ pared with the pooled ESTEEM 1 and 2 population $(66.6 \mathrm{~mm}, 58.2 \mathrm{~mm})$. These findings are consistent with other real-world studies that reported use of apremilast in more moderate psoriasis $[19,21,24]$ compared with the phase 3 
Table 3 Overview of adverse events, most commonly reported adverse events and treatment-related serious adverse events

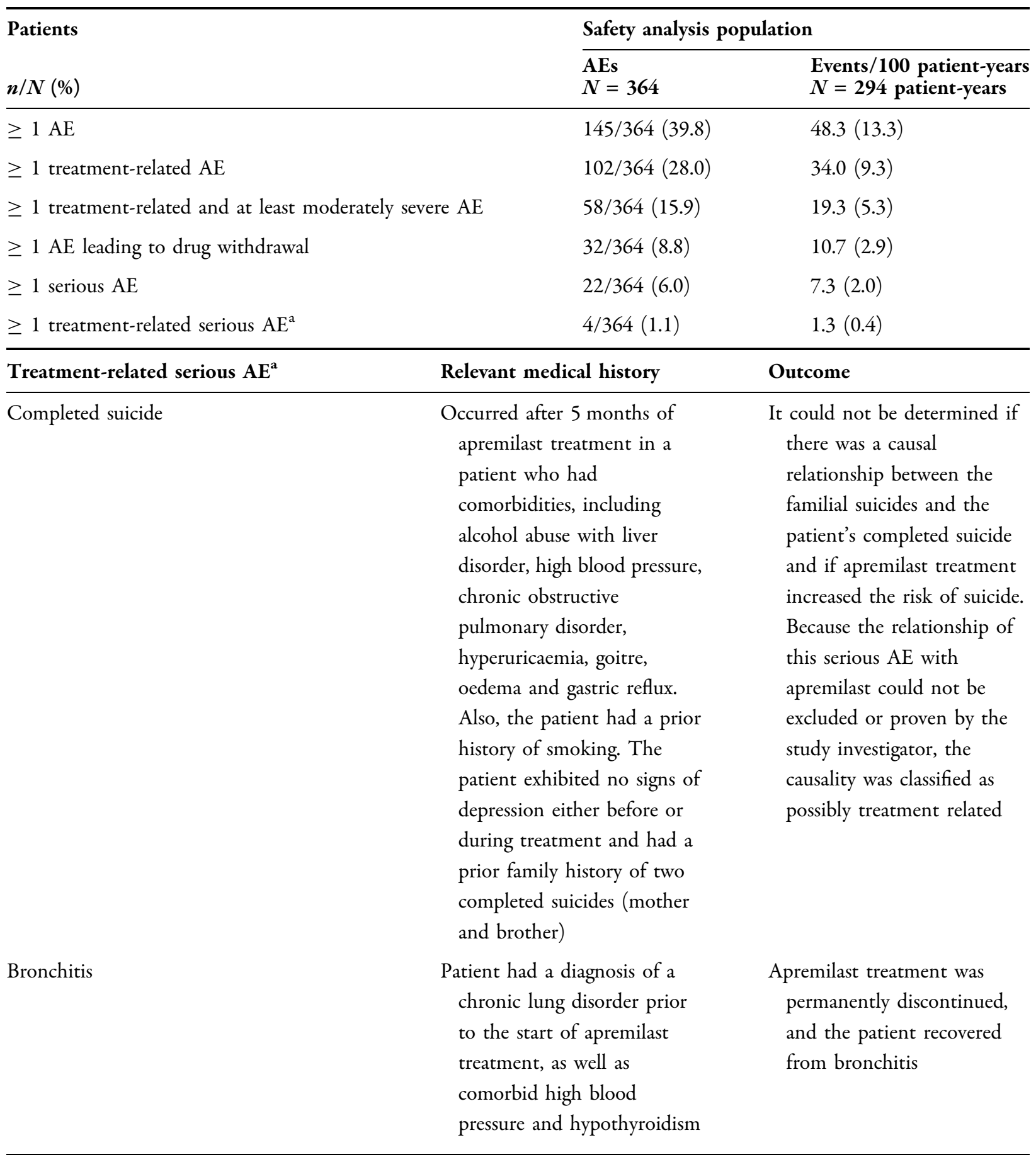


Table 3 continued

\begin{tabular}{lcc}
\hline Treatment-related serious $\mathbf{A E}^{\mathbf{a}}$ & Relevant medical history & Outcome \\
\hline Weight loss & Patient who lost $9 \mathrm{~kg}$ after & Apremilast treatment was \\
& 5 months of apremilast & temporarily interrupted in \\
this patient in accordance & with the apremilast Summary \\
& hypertension, type 1 diabetes & of Product Characteristics \\
& mellitus, diarrhoea, & \\
& dyslipidaemia and & \\
& hyperthyroidism & Apremilast was permanently \\
Seizure (including racing heart and tremor) & Occurred after 2 months of & discontinued, and the patient \\
& apremilast treatment in a & recovered from this AE \\
& patient who had comorbid & \\
& high blood pressure, & \\
& hypercholesterolaemia, & \\
kidney failure, type 2 & \\
diabetes, heart failure and & \\
& aortic stenosis &
\end{tabular}

\begin{tabular}{|c|c|c|}
\hline \multirow{2}{*}{$\begin{array}{l}\text { AEs in } \geq 5 \% \text { of patients in clinical trials of apremilast }{ }^{1,2} \\
n / N(\%)^{b}\end{array}$} & \multicolumn{2}{|c|}{ LAPIS-PSO safety analysis population } \\
\hline & $\begin{array}{l}\text { Most frequent } \\
\text { AEs } \\
N=364\end{array}$ & $\begin{array}{l}\text { Events per } 100 \text { patient-years } \\
N=294 \text { patient-years }\end{array}$ \\
\hline Diarrhoea & $33 / 364(9.1)$ & $11.0(3.0)$ \\
\hline Headache $^{c}$ & $23 / 364(6.3)$ & $7.7(2.1)$ \\
\hline Nausea & $18 / 364(4.9)$ & $6.0(1.6)$ \\
\hline URTI $^{\mathrm{d}}$ & $2 / 364(0.5)$ & $1.3(0.4)$ \\
\hline Median time to first occurrence ${ }^{e}$ & $N$ & Median time, days \\
\hline Diarrhoea & 32 & 7.0 \\
\hline Headache & 23 & 9.0 \\
\hline Nausea & 18 & 5.5 \\
\hline URTI & 3 & 13.0 \\
\hline
\end{tabular}

$A E$ adverse event, URTI upper respiratory tract infection

${ }^{a}$ Causality suspected or cannot be excluded according to investigator

${ }^{\mathrm{b}}$ AEs with a causal relationship to apremilast treatment

${ }^{\mathrm{c}}$ Tension headache was reported in one patient $(0.3 \%)$

${ }^{\mathrm{d}}$ Treatment-related nasopharyngitis was reported in two patients $(0.5 \%)$

${ }^{\mathrm{e}} \mathrm{AEs}$ with or without a causal relationship to apremilast treatment. AEs with a start date before baseline were excluded from this analysis 
pivotal clinical trials, which enrolled biologicexperienced patients with moderate to severe psoriasis $[13,14]$. Despite lower disease severity, mean baseline DLQI score was somewhat higher in LAPIS-PSO (14.1) compared with the pooled population of ESTEEM 1 and 2 (12.7). This observation agrees with other observations that DLQI does not necessarily correlate with disease severity [15] but may correlate with psoriasis involvement in special areas [6]; this finding may also reflect less restrictive eligibility criteria in this real-world study than in the ESTEEM trials, which excluded patients with other clinically significant or major uncontrolled comorbid diseases or infections [13, 14].

Psoriasis involvement in special areas (i.e. sensitive and visible areas), such as the scalp, nails and palmoplantar areas, was prevalent in LAPIS-PSO patients. The proportion of patients with psoriasis involvement in special areas in LAPIS-PSO (i.e. scalp 80\%, nail 51\% and palmoplantar 27\%) was higher than in other prior studies (i.e. scalp $43-52 \%$, nail $23-33 \%$ and palmoplantar 14\%) [25-27] and likely contributed to the high QOL impairment observed in LAPIS-PSO. In addition to QOL improvements, apremilast was associated with early and sustained improvements in the severity of scalp, nail and palmoplantar involvement.

Baseline mean DLQI scores were lower in other real-world studies of apremilast $(\sim 11.0)$ $[22,28]$, possibly due to differences in patient populations. Unlike LAPIS-PSO, other realworld studies did not require patients to be treated as described in the SmPC (e.g. systemicnaive patients were permitted [28] or patients were not required to have moderate to severe psoriasis at baseline [22]). Mean baseline DLQI score in LAPIS-PSO (14.1) was comparable to the recent APPRECIATE real-world study (13.4), a retrospective, non-interventional study that also included patients who initiated apremilast in clinical practice per the SmPC [19].

Achievement of $\geq 5$-point improvement in DLQI score at $\sim 4$ months (when the primary endpoint was assessed) was generally comparable in LAPIS-PSO (61.4\%) to the pooled ESTEEM 1 and 2 studies (66.4\%); the UNVEIL study $(63.8 \%)$ of apremilast in patients with moderate plaque psoriasis (BSA 5-10\%); and a recent chart review study of patients receiving apremilast for moderate to severe plaque psoriasis in clinical practice $(63.6 \%)[15,22]$.

Patients in both PGA severity subgroups in LAPIS-PSO had similar rates of $\geq 5$-point improvement in DLQI score (moderate PGA: 59.9\%; severe PGA: $60.8 \%$ ) at the $\sim 4$-month visit that were comparable to those observed in UNVEIL (63.8\%) at week 16, when the primary analysis of UNVEIL was reported [15]. Despite similar achievement of DLQI response in both PGA severity subgroups over time, greater proportions of patients with less severe psoriasis achieved early PASI treatment response versus patients with more severe psoriasis. Although patients with a PGA score of 2 or 3 had less skin involvement than those with a PGA score of 4 , the two groups reported similar baseline disease burden, perhaps due to similar rates of scalp and nail involvement. Our findings suggest that the initiation of systemic therapies and effective interventions targeting psoriasis symptoms and special areas should be considered earlier in the course of disease severity, for example in patients with less skin disease but high disease burden due to psoriasis in special areas.

As noted in other real-world studies of apremilast [21, 22, 29], the most commonly reported AEs of diarrhoea, headache, nausea and upper respiratory tract infection were consistent with those reported in placebo-controlled trials [13-15, 30]. Strategies such as nonmedical approaches (e.g. taking apremilast with a meal, adequate diet and hydration), antidiarrhoeal or anti-nausea medication, or probiotic use can help manage mild to moderate gastrointestinal AEs [31]. Many patients in LAPISPSO reported that they preferred apremilast and found it to be better tolerated than their prior systemic treatment. Taken together, findings from LAPIS-PSO are consistent with results from clinical trials of apremilast and provide additional information about patients' experiences with apremilast treatment in clinical practice settings.

This study was limited by its non-interventional design, which can be susceptible to incomplete data collection. In addition to the as-observed analyses, we imputed missing values using LOCF to ensure that results would be 
representative of the entire study population. No major differences were observed using the two statistical methodologies. Although the number of patients analysed for the primary endpoint $(n=257)$ was slightly lower than planned $(n=290)$, no formal statistical analyses were performed and findings were consistent with the known efficacy and safety of apremilast as reported in clinical trials [13-16].

\section{CONCLUSION}

In conclusion, treatment with apremilast was associated with improvements in QOL and psoriasis disease severity that were sustained up to $\sim 13$ months, including patients with less severe and more severe psoriasis. These data confirm that apremilast can benefit patients who have high disease burden due to psoriasis in special areas and provide meaningful and sustained improvements in bothersome symptoms such as itch and skin pain. The safety profile of apremilast in this real-world study was consistent with the known safety profile observed in clinical trials.

\section{ACKNOWLEDGEMENTS}

We thank the patients and physicians who participated in the study.

Medical writing/editorial assistance. Writing support was funded by Amgen Inc. and provided by Amy Shaberman, PhD, and Kristin Carlin, BSPharm, MBA, of Peloton Advantage, LLC, an OPEN Health company, and Mandy Suggitt, Amgen Inc.

Disclosures. Kristian Reich: AbbVie, Affibody, Almirall, Amgen Inc., Biogen, Boehringer Ingelheim, Celgene Corporation, Centocor, Covagen, Fresenius Medical Care, Janssen-Cilag, Miltenyi Biotec, Ortho Biotech, Eli Lilly, Forward Pharma, GlaxoSmithKline, Kyowa Hakko Kirin Pharma, LEO Pharma, Lilly ICOS, Medac Pharma, Merck \& Co., Novartis, Pfizer, Regeneron, Samsung, Sanofi, Takeda, UCB, Valeant, and XenoPort-speaker/advisory board/data safety monitoring board, honoraria. Bernhard Korge: AbbVie, Almirall, Amgen, Astella, Beiersdorf, Biogen, Celgene, Dr. Pfleger, Galderma, Janssen, LEO Pharma, Lilly, Novartis, Medac, Sanofi, and UCB-served as an advisor. Nina Magnolo: AbbVie, Asana, Biogen, Boehringer Ingelheim, Celgene Corporation, Dr. Reddy's Laboratories, Eli Lilly, Galderma, Genentech, Incyte, Janssen-Cilag, Kyowa Kirin, LEO Pharma, MSD, Novartis, Pfizer, Regeneron, Sun Pharma, and UCB Pharma-honoraria, advisor, and/or paid speaker for and/or participated in clinical trials. Maria Manasterski: Nothing to disclose. Uwe Schwichtenberg: AbbVie Deutschland GmbH, Almirall Hermal GmbH, Amgen, Beiersdorf Dermo Medical $\mathrm{GmbH}$, Celgene $\mathrm{GmbH}$, Janssen Cilag $\mathrm{GmbH}$, Johnson \& Johnson GmbH, LEO Pharma $\mathrm{GmbH}$, L'Oréal GmbH, MEDA Pharma GmbH, Medical Project Design GmbH, Merz Pharmaceuticals GmbH, MSD SHARP \& DOHME $\mathrm{GmbH}$, Novartis Pharma $\mathrm{GmbH}$, and Pfizer $\mathrm{GmbH}$-salary, investigator, advisory board, speaker, and/or stockholder. Petra StaubachRenz: Amgen and Celgene $\mathrm{GmbH}$-personal fees, non-financial support. Stephan Kaiser, Josefine Roemmler-Zehrer, and Katrin LorenzBaath: Amgen $\mathrm{GmbH}$-former employment. Natalie Núnez Gómez: Bristol Myers Squibbformer employment. Celgene Corporationemployment at the time of study conduct.

Compliance with ethics guidelines. An independent ethics committee (FEKI; Freiburger Ethikkommission International, reference 015/1385) approved the study protocol, and all patients provided written, informed consent before participating. Local ethics committees approved the protocol for participating study sites (UK RUB Ruhruniversität Bochum, reference 52/2015; Sächsische Landesärztkammer, reference RN EK-BR-74/15-1; Medizinische Fakultät Mannheim, reference 2015-905W-MA; Ethikkommission der Technischen Universität Dresden, reference EK472112015; Medizinische Fakultät der Universität Duisburg-Essen, reference 16-6844-BO). The study was conducted in accordance with the ethical principles outlined in the Declaration of Helsinki and its later amendments. 
Funding. This study was funded by Celgene and Amgen. Amgen acquired the worldwide rights to Otezla ${ }^{\circledR}$ (apremilast) on November 21, 2019. Writing support and the journal's Rapid Service fee were funded by Amgen Inc.

Authorship. All named authors meet the International Committee of Medical Journal Editors (ICMJE) criteria for authorship for this article, take responsibility for the integrity of the work as a whole, and have given their approval for this version to be published.

Author contributions. KR, SK, JR-Z, NNG, and KL-B contributed to the study conception and design. Material preparation, data collection, and/or analysis were performed by KR, BK, NM, MM, US, PS-R, SK, JR-Z, NNG, and KL-B. All authors contributed to drafting of the manuscript and approved the final manuscript.

Data availability. The datasets generated and/or analyzed during the current study are available from the corresponding author on reasonable request.

Prior presentation. Reich K, Fritzlar S, Korge $\mathrm{B}$, et al. Physician- and Patient-Reported Outcomes in Patients With Moderate to Severe Plaque Psoriasis Treated With Apremilast During Routine Dermatology Care in Germany. Presented at: Deutsche Dermatologische Gesellschaft (DDG) Dermatologie Kompakt \& Praxisnah 2020; February 7-9, 2020; Dresden, Germany.

Open Access. This article is licensed under a Creative Commons Attribution-NonCommercial 4.0 International License, which permits any non-commercial use, sharing, adaptation, distribution and reproduction in any medium or format, as long as you give appropriate credit to the original author(s) and the source, provide a link to the Creative Commons licence, and indicate if changes were made. The images or other third party material in this article are included in the article's Creative Commons licence, unless indicated otherwise in a credit line to the material. If material is not included in the article's Creative Commons licence and your intended use is not permitted by statutory regulation or exceeds the permitted use, you will need to obtain permission directly from the copyright holder. To view a copy of this licence, visit http://creativecommons.org/licenses/by$\mathrm{nc} / 4.0 /$.

\section{REFERENCES}

1. Baliwag J, Barnes DH, Johnston A. Cytokines in psoriasis. Cytokine. 2015;73:342-50.

2. Lebwohl MG, Bachelez H, Barker J, Girolomoni G, Kavanaugh A, Langley RG, et al. Patient perspectives in the management of psoriasis: results from the population-based Multinational Assessment of Psoriasis and Psoriatic Arthritis Survey. J Am Acad Dermatol. 2014;70:871-81.

3. Langley RG, Krueger GG, Griffiths CE. Psoriasis: epidemiology, clinical features, and quality of life. Ann Rheum Dis. 2005;64(Suppl 2):18-23.

4. Merola JF, Qureshi A, Husni ME. Underdiagnosed and undertreated psoriasis: nuances of treating psoriasis affecting the scalp, face, intertriginous areas, genitals, hands, feet, and nails. Dermatol Ther. 2018;31:e12589.

5. Mrowietz U, Kragballe K, Reich K, Spuls P, Griffiths $\mathrm{CE}$, Nast A, et al. Definition of treatment goals for moderate to severe psoriasis: a European consensus. Arch Dermatol Res. 2011;303:1-10.

6. Augustin M, Sommer R, Kirsten N, Danckworth A, Radtke MA, Reich K, et al. Topology of psoriasis in routine care-results from a high-resolution analysis in 2009 patients. Br J Dermatol. 2019;181: 358-65.

7. Sommer R, Augustin M, Mrowietz U, Topp J, Schafer I, von Spreckelsen R. Perception of stigmatization in people with psoriasis - qualitative analysis from the perspective of patients, relatives and healthcare professionals. Hautarzt. 2019;70:520-6.

8. Armstrong AW, Robertson AD, Wu J, Schupp C, Lebwohl MG. Undertreatment, treatment trends, and treatment dissatisfaction among patients with psoriasis and psoriatic arthritis in the United States: findings from the National Psoriasis Foundation surveys, 2003-2011. JAMA Dermatol. 2013;149: 1180-5.

9. Menter A, Korman NJ, Elmets CA, Feldman SR, Gelfand JM, Gordon KB, et al. Guidelines of care for the management of psoriasis and psoriatic arthritis: 
section 6. Guidelines of care for the treatment of psoriasis and psoriatic arthritis: case-based presentations and evidence-based conclusions. J Am Acad Dermatol. 2011;65:137-74.

10. Deeks ED. Apremilast: a review in psoriasis and psoriatic arthritis. Drugs. 2015;75:1393-403.

11. Schafer P. Apremilast mechanism of action and application to psoriasis and psoriatic arthritis. Biochem Pharmacol. 2012;83:1583-90.

12. Otezla. Summary of product characteristics. Breda: Amgen Europe B.V.; 2020.

13. Papp K, Reich K, Leonardi CL, Kircik L, Chimenti S, Langley RG, et al. Apremilast, an oral phosphodiesterase 4 (PDE4) inhibitor, in patients with moderate to severe plaque psoriasis: results of a phase III, randomized, controlled trial (Efficacy and Safety Trial Evaluating the Effects of Apremilast in Psoriasis [ESTEEM 1]). J Am Acad Dermatol. 2015;73: 37-49.

14. Paul C, Cather J, Gooderham M, Poulin Y, Mrowietz U, Ferrandiz C, et al. Efficacy and safety of apremilast, an oral phosphodiesterase 4 inhibitor, in patients with moderate to severe plaque psoriasis over 52 weeks: a phase III, randomized, controlled trial (ESTEEM 2). Br J Dermatol. 2015;173:1387-99.

15. Strober B, Bagel J, Lebwohl M, Stein Gold L, Jackson JM, Chen R, et al. Efficacy and safety of apremilast in patients with moderate plaque psoriasis with lower BSA: week 16 results from the UNVEIL study. J Drugs Dermatol. 2017;16:801-8.

16. Reich K, Gooderham M, Bewley A, Green L, Soung J, Petric R, et al. Safety and efficacy of apremilast through 104 weeks in patients with moderate to severe psoriasis who continued on apremilast or switched from etanercept treatment: findings from the LIBERATE study. J Eur Acad Dermatol Venereol. 2018;32:397-402.

17. Van Voorhees AS, Gold LS, Lebwohl M, Strober B, Lynde C, Tyring S, et al. Efficacy and safety of apremilast in patients with moderate to severe plaque psoriasis of the scalp: results of a phase $3 \mathrm{~b}$, multicenter, randomized, placebo-controlled, double-blind study. J Am Acad Dermatol. 2020;83: 96-103.

18. Masson Regnault M, Castañeda-Sanabria J, Diep Tran MHT, Beylot-Barry M, Bachelez H, Beneton N, et al. Users of biologics in clinical practice: would they be eligible for phase III clinical studies? Cohort Study in the French Psoriasis Registry PSOBIOTEQ. J Eur Acad Dermatol Venereol. 2020;34:293-300.
19. Augustin M, Kleyn CE, Conrad C, Sator PG, Stahle $\mathrm{M}$, Eyerich $\mathrm{K}$, et al. Characteristics and outcomes of patients treated with apremilast in the real world: results from the APPRECIATE study. J Eur Acad Dermatol Venereol. 2021;35:123-34.

20. Reich A, Medrek K, Stander S, Szepietowski JC. Determination of minimum clinically important difference (MCID) of visual analogue scale (VAS): in which direction should we proceed? [abstract IL26]. Acta Derm Venereol. 2013;93:609-10.

21. Mayba JN, Gooderham MJ. Real-world experience with apremilast in treating psoriasis. J Cutan Med Surg. 2017;21:145-51.

22. Papadavid E, Rompoti N, Theodoropoulos K, Kokkalis G, Rigopoulos D. Real-world data on the efficacy and safety of apremilast in patients with moderate-to-severe plaque psoriasis. J Eur Acad Dermatol Venereol. 2018;23:1173-1179.

23. Knuckles MLF, Levi E, Soung J. Treating moderate plaque psoriasis: prospective 6-month chart review of patients treated with apremilast. J Dermatol Treat. 2019;30:430-4.

24. Vujic I, Herman R, Sanlorenzo M, Posch C, Monshi $\mathrm{B}$, Rappersberger K, et al. Apremilast in psoriasis-a prospective real-world study. J Eur Acad Dermatol Venereol. 2018;32:254-9.

25. Merola JF, Li T, Li WQ, Cho E, Qureshi AA. Prevalence of psoriasis phenotypes among men and women in the USA. Clin Exp Dermatol. 2016;41: 486-9.

26. Egeberg A, See K, Garrelts A, Burge R. Epidemiology of psoriasis in hard-to-treat body locations: data from the Danish skin cohort. BMC Dermatol. 2020;20:3.

27. Augustin M, Langenbruch A, Gutknecht M, Reich $\mathrm{K}$, Korber A, Maassen D, et al. Definition of psoriasis severity in routine clinical care: current guidelines fail to capture the complexity of long-term psoriasis management. Br J Dermatol. 2018;179:1385-91.

28. Augustin M, Spehr C, Radtke MA, Boehncke WH, Luger T, Mrowietz U, et al. German psoriasis registry PsoBest: objectives, methodology and baseline data. J Dtsch Dermatol Ges. 2014;12:48-57.

29. Ighani A, Georgakopoulos JR, Zhou LL, Walsh S, Shear N, Yeung J. Efficacy and safety of apremilast monotherapy for moderate to severe psoriasis: retrospective study. J Cutan Med Surg. 2018;22:290-6.

30. Reich K, Gooderham M, Green L, Bewley A, Zhang $Z$, Khanskaya I, et al. The efficacy and safety of 
apremilast, etanercept, and placebo, in patients with moderate to severe plaque psoriasis: 52-week results from a phase $3 \mathrm{~b}$, randomized, placebo-controlled trial (LIBERATE). J Eur Acad Dermatol Venereol. 2017;31:507-17.
31. Pinter A, Beigel F, Körber A, Homey B, Beissert S, Gerdes S, et al. Gastrointestinal side effects of apremilast: characterization and management. Hautarzt. 2019;70:354-62. 